\title{
GEOMATICS AND ARCHAEOMETRIC INVESTIGATIONS FOR THE SUSTAINABLE REUSE OF RUINS. THE SANTA CHIARA CONVENT RUIN IN CAGLIARI (SARDINIA)
}

\author{
D.R. Fiorino ${ }^{1}$, S.M. Grillo ${ }^{2}$, E. Pilia ${ }^{1}$, G. Vacca $^{1}$ \\ ${ }^{1}$ DICAAR, Dept. of Civil-Environmental Engineering and Architecture, Cagliari, Italy - (donatella.fiorino, epilia, vaccag)@ unica.it \\ ${ }^{2}$ DSCG Dept. of Chemical and Geological Science, University of Cagliari, Italy - grillo@ unica.it
}

Commission VI, WG VI/4

KEY WORDS: ruined heritage, TLS techniques, stratigraphies, diagnostic, preservation.

\begin{abstract}
:
The ruined convent of Santa Chiara, a nodal urban space connecting three historic quarters of Cagliari, has had a key role in the urban life of the city since medieval age. After the suppression of the mendicant orders in 1864 and the violent bombings during the World War II, this monument become a neglected and ruined shell of masonry with no roofs and floors, losing its central role. Several interventions for its conversion as temporal local market and the following restoration and integration works have contributed to stratify these structures nowadays not accessible but valuable benchmarks for reconstructing the history and evolution of the fabric, still unclear. Starting from the archival and bibliographic investigations, then a geomatics and archaeometric investigations of the fabric have allowed to understand and study the building's forms, geometries, materials, developments, and chronologies. They have also permitted to recognise characteristic features or anomalies, structural morphology, and other structural issues, significant for the definition of sustainable project of reuse.
\end{abstract}

\section{INTRODUCTION}

The paper presents the ruined convent of Santa Chiara as case study included in a wider research on ruined architectures placed in rural and urban contexts at the international scale (1) (Pilia, 2019). In particular, this research stems from the unresolved debate around the complexity of these fragmented and misunderstood structures, the difficulty concerning their interpretation and the consequent controversial practical modalities nowadays designed for their preservation and reuse. The issues concerning the scarce compatibility and the wrong level of intervention on ruins can be found both on the dialectic relationship between restoration and architectural and urban design, and on the absence of an in-depth preliminary project of investigation for the holistic knowledge of the fabric upon which base the intervention. After a worldwide examination of the state of the art on the topic, it has been considered essential the codification of an interoperable and transdisciplinary protocol of investigation carried out by a research team of the School of Architecture of the University of Cagliari with the further collaboration of the Scottish Centre for Conservation Studies (2), that includes different academic fields: geomatic (3), restoration and geomaterials (4). This partnership has

\footnotetext{
* Corresponding author
}

(1) The research has been carried out by Elisa Pilia during the Europeaus Doctorate in Civil Engineering and Architecture, XIX cycle with the thesis entitled "Uban ruins. Memorial value and contemporary role" supervised by Donatella Rita Fiorino, Caterina Giannattasio, Silvana Maria Grillo (University of Cagliari) and Ruxandra-Iulia Stoica (University of Edinburgh).

(2) ESALA, Edinburgh School of Architecture and Landscape Architecture, University of Edinburgh.

(3) DICAAR, Unity of Geomatic of the DICAAR; scientific coordinator: prof. G. Vacca. allowed a comparative investigation between the Anglo-Saxon and Italian contexts, arriving at defining an integrated methodology where ruins are investigated in strict connection with their context, and the understanding of their geometry, materials, techniques and technologies supporting the assessment of values and significance of these architectures for their respectful interventions - conservation or integration - and enhancement.

The protocol experimented both on rural (Fiorino, et. al., 2014, 2015a, 2015b, 2014, 2017; Pilia et. al., 2016) and urban ruins (Fiorino, et. al., 2017; Giannattasio et. al., 2013), finds here its application on the urban ruined conventual complex of Santa Chiara, chosen for its strategic position into the historical core (Pilia, 2017).

\section{THE CASE STUDY: SANTA CHIARA RUINS}

The convent ruin, part of a monumental complex that also included the baroque Santa Chiara church and the local Santa Chiara market, is located in the quartier of Stampace on the western side of the Castello hill in a flat area between the Santa Croce Bastions, Via Santa Margherita and Piazza Yenne, a nodal urban space connecting the three historic quarters of Stampace, Castello and Marina (figure 1 - 2).

(4) DICAAR, LabMAST - Mediterranean Laboratory for Historical materials and architectures. 


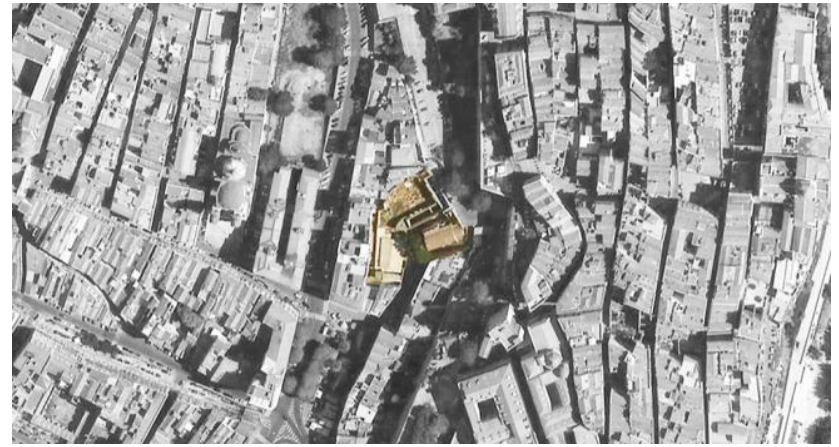

Figure 1. Localisation of the ruined complex of Santa Chiara (Pilia E.)

The importance of its strategic position also relates to the significant changes in level between Piazza Yenne and via Cammino Nuovo. In the 1858, the engineer Gaetano Cima designed a monumental staircase along what was an arduous path on the north-east side of the church. Then, in the 1990s, the city council installed a public lift in the convent's ruined structure. Nevertheless, the site's current strategic role was not conceived for the original building; it was a monument built in a corner of the inner centre completely isolated from the rest of the urban fabric. Nowadays, although recently restored and structurally repaired in 2016, the convent is still in an ongoing state of ruination because of the nature of its building material: the pietra cantone. The building's structural conditions can be considered as average, where the loss of structural parts (50\%) has compromised the legibility of the original building and its unplastered materials continue their process of decay. Overall, for its central position, its good accessibility - although it is closed to the public - and state of conservation, these ruins have been considered an interesting structure, still not enough studied, to test the methodology.

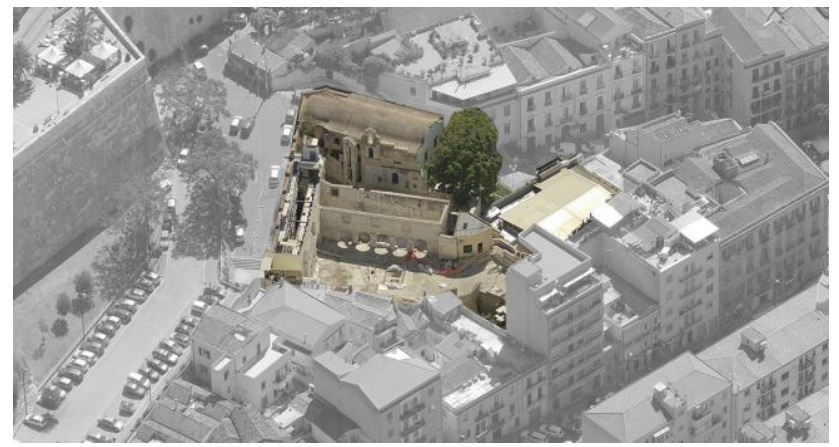

Figure 2. Aerial view on $45^{\circ}$ of the ruins (Pilia E.).

\section{METHODOLOGY}

\subsection{The integrated protocol (D.R.F)}

Considered the reading complexity of this ruined structure and the scarce presence of archival sources as well as the consequent problems concerning its reuse, the integrated protocol of analysis (Fiorino, 2015) has been divided in four interoperable phases.

First, the ruin was carefully explored through an accurate survey protocol. Although the monumental complex does not present any material impediment to the surveys, its geometrical complexity, the presence of different levels and macroscopic structural anomalies as well as the numerous stratigraphies discovered during a first traditional topographic survey, led to the decision to support geometric knowledge with the greater accuracy provided by Terrestrial Laser Scanner techniques (TLS) and GPS survey. In particular, during the phase of restitution and editing, a more accurate study of the geometric characteristics of the vertical and horizontal structures was prepared. In fact, the aim of the TLS survey was not only to provide the graphic documentation to support the final project such as plans, sections and elevations but also to investigate possible anomalies or stratigraphies of the building (Giannattasio et al., 2013). For that reason, a series of graphic outputs were extracted from the convent's 3D model. Specifically, horizontal sections were performed reconstructing the significant plans that could better represent the stratigraphies of the structures such as the addition of walls, opening or closing of windows and so on. Also, vertical sections were used for analysing the depth of the cisterns as well as for studying the verticality of some walls. Especially one has been analysed in depth and a series of vertical sections were processed every $1 \mathrm{~cm}$ in order to obtain the map of vertical anomalies. While the first detailed analysis was useful for the stratigraphic analysis of the entire complex, the second was fundamental for understanding the structures' structural conditions. Starting from these accurate survey, archaeometric investigations were carried out with an archaeological approach consisting of stratigraphic analysis, mineral petrographic investigations of historic materials, and the identification and analysis of building techniques. Stratigraphic analysis carried out both on the elevations and in plan was aimed at reconstructing its relative chronologies. Then, for clarifying the stratigraphic analysis and understanding of the relative chronologies, a miner-petrographic analysis was conducted. The protocol considered a rational sampling in view of the different kinds of mortars used, where and how they were placed, also taking into account the previous investigations. The sampling was made according to specific goals: the qualitative characterisation of the materials due to their compatible reintegration and the identification of their chrono-typology to support the building's overall chronology given by the stratigraphic analysis of the masonries. The stratigraphic and minero-petrographic analyses of the building ultimately led to the classification of specific masonry techniques, widely influenced not only by economic and cultural factors, but also by local geological features and native materials with their mechanical and technological properties. Overall, the integration of geomatics and archaeometric studies have been fundamental not only to reconstruct the history of the fabric but also for investigating the state of conservation of the structure defining their relative chronology and identifying their tangible and intangible values, basis for the future sustainable project of reuse.

\subsection{Archival documentation (E.P.)}

The monument, occupied by the order of Clarisse nuns, was built in the 14th century on an existing church dedicated to Santa Margherita outside the city's medieval defence walls. This existing structure is confirmed by an inscription found in the church and dedicated to this saint. It is also present in a series of documents, such as one dated 1263 in which the church is mentioned but with no reference to the Clarisse order. The cloistered convent, located strategically near the Convent of Franciscan monks also located in Stampace, had a structure entirely closed upon itself with no connections to the nearby urban context. Information regarding its foundation is poor but it is possible to reconstruct the general life and history of the 
nuns through the accurate investigation of the bibliographical, iconographic and archival sources.

The first information can be found in two royal laws dating from 1328. These documents refer to the name, 'monks of Stampace', the assignment to the order of '200 staterelli of grain' and the number of the nuns as 50. In 1338, another royal communication forbade the community to move and inhabit the Santa Chiara area, so it is possible to understand that some buildings had already been constructed in the area and that the nuns were already there. The direct administration of the Franciscan order on this convent ended in 1585 when the Apostolic Seat decided to take control. From the seventeenth century on and during the entire reign of the House of Aragon, the convent existed in absolute privacy. During the 17th century, little but important information came from sworn testimonies by notary Giovanni Spada. In 1604, he reported on the convent's desperate economic situation. For that reason, the archbishop Alfonso Laso Sedeno decided to restore the dormitory, to build new walls and to refurbish the cistern and other parts of the convent (Ingegno 1993, 33). The number of the nuns started to decrease from this period onward. As is known from the archival documents, only thirty nuns lived in the convent in 1602. During the same century, the baroque church was built in its current form and the convent was probably enlarged during some restoration works. Indeed, relationships changed with its surroundings as it began to play a significant role in the city's urbanisation and economy. At the end of the 18th century the convent was described as 'an unhealthy place', especially the dormitory due to its location near the humid embankment. As a consequence of its structural obsolescence, the order sharply declined in the 19th century.

Moreover, in 1864, the national law for the suppression of the mendicant orders contributed to closing the convent and its consequent downfall. On 28th October of the same year, the nuns were relocated in another convent ' $\mathrm{La}$ Purissima' in Castello and then, in June, they returned to the old Santa Chiara structures. After these events, in 1866 the area was sold to the Council (Act n. 1292, 15th January 1897; notary Giuseppe Sulis). The same council then left the building to the State in 1911 for its complete demolition and new construction of offices for the fiscal police. As the superintendent for the Sardinian monuments Doro Levi asserted, the complex did not hold any particular importance in historical and artistic terms due to its poor conditions and the site was not adequate for this new use and the property passed again into the hands of the council. With the closure of the Convent in the 20th century and its consequent desertion, the area lost its central role to become a neglected place. In 1943, WWII bombing destroyed part of the structures and the consequent clean-up returned a ruined shell of masonry with no roofs and floors. Several unappropriated new uses and restoration works.

In 1957, a temporary local market was installed inside the convent transforming the space with new roofs, floors and partitions (fig, 2). At the time, the area became important again, although in a different way from its previous religious role, having been a point of convergence for Castello, Stampace and Marina. Due to this significant role, and the convent's importance, the Council moved the market close to the Church access stairs where, in 1984-85, the Superintendence carried out important archaeological excavations on the structure; it also performed some structural renovations and repairs with compatible materials. In the 1990 s, the decision to install a lift in the space between the church and the convent, the original location of the confessionals and oratories, raised additional issues in terms of the legibility of the structures, perceived as two different buildings. Today's disuse of the lift has intensified the abandonment of this place and, notwithstanding the recent restoration and integration work by the Superintendence (designed by Architect Paolo Margaritella), nobody can access these structures.

\subsection{Geomatic survey (G. V.)}

The ruin of the Santa Chiara convent has been carefully investigated through an accurate survey protocol. Although the monumental complex does not present any material impediment to the surveys, its geometrical complexity, the presence of different levels and macroscopic structural anomalies as well as the numerous stratigraphies discovered during the traditional topographic survey, led to the decision to support geometric knowledge with the greater accuracy provided by terrestrial laser scanner techniques (TLS) and GPS survey. As for all cultural heritage, the plan geometry, elevations and vertical sections were the starting points for the study of the building. The presence of a prior and unknow geometrical survey with plan and elevations, and the awareness of some inaccuracies, led to the decision to use the TL techniques essentially for the virtual reconstruction of the entire convent. This type of survey was carried out with the technical support of the Unity of Geomatic of the DICAAR; the laser scanner Faro Focus 3D, was utilized. The TLS survey consisted of three phases: scan acquisition, the GPS survey for georeferencing the point clouds; data processing of the cloud and restitution and editing of the graphic outputs.

With its versatility and light weight, the laser Focus $3 \mathrm{D}$ allowed us to perform 33 scans (figure $3 \mathrm{~b}$ ) with density point of $3 \mathrm{~mm}$, up to $120 \mathrm{~m}$ distance with high speed point acquisition up to 976.000 points/second. For all stations, the resolution was $1 / 4$, with quality $3 \mathrm{x}$, distance $\mathrm{mm} / 10 \mathrm{~m}$ and 6.136 . Only for S23 and $\mathrm{S} 24$, performed in the stairs, the resolution was $1 / 5$. Overall, for accuracy and precision, the survey was compatible with a restitution of drawings in scale 1:10 such as those required for archaeological investigation.

The survey took 5 hours and the weather conditions were optimal with the absence of direct bright light on the walls. Following acquisition, the data processing of the point clouds, carried out with JRC 3D Reconstructor software, consisted of: cleaning of point clouds, manual deletion of points; alignment of single scans (or scans registration), georeferencing of clouds of points, triangulation and performing mesh, closure of mesh and correction of abnormal faces, performance of orthophotos, performance of 3D model (figure 3a) of site and restitutions and graphic renders. During the phase of restitution and editing, a more accurate study of the geometric characteristics of the vertical and horizontal structures was prepared. In fact, the aim of the TLS survey was not only to provide the graphic documentation to support design such as plans, sections and elevations but also to investigate possible anomalies or stratigraphies of the building.

For that reason, a series of graphic outputs were extracted from the convent's 3D model. Specifically, horizontal sections were performed every $10 \mathrm{~cm}$ from the lower level of the convent (34 $\mathrm{m}$ above the sea level) to the highest point of the walls.

These were useful in reconstructing several significant plans that could better explain the stratigraphies of the structures such as the addition of walls, opening or closing of windows and so on. In addition, vertical sections were used for analysing the depth of the cisterns as well as for studying the verticality of some walls. Especially one wall (figure 3c) different in thickness from the others, was analysed in depth and a series of vertical sections were processed every $1 \mathrm{~cm}$ in order to obtain the map of vertical anomalies. 
While the first detailed analysis was useful for the stratigraphic analysis of the entire complex, the second one was fundamental for understanding the structures' structural conditions.

Overall, these surveys offered an accurate restitution of the building's forms, geometries and details. All were essential for clearly identifying the tangible values strictly linked to functional and evidentiary aspects, which, without TSL, we would not be able to assess. Indirectly, they also contributed to identifying practices and relationships such as those linked to the artisans and technologies from different centuries. An archaeometric investigation was carried out after the survey phase to discover these aspects.
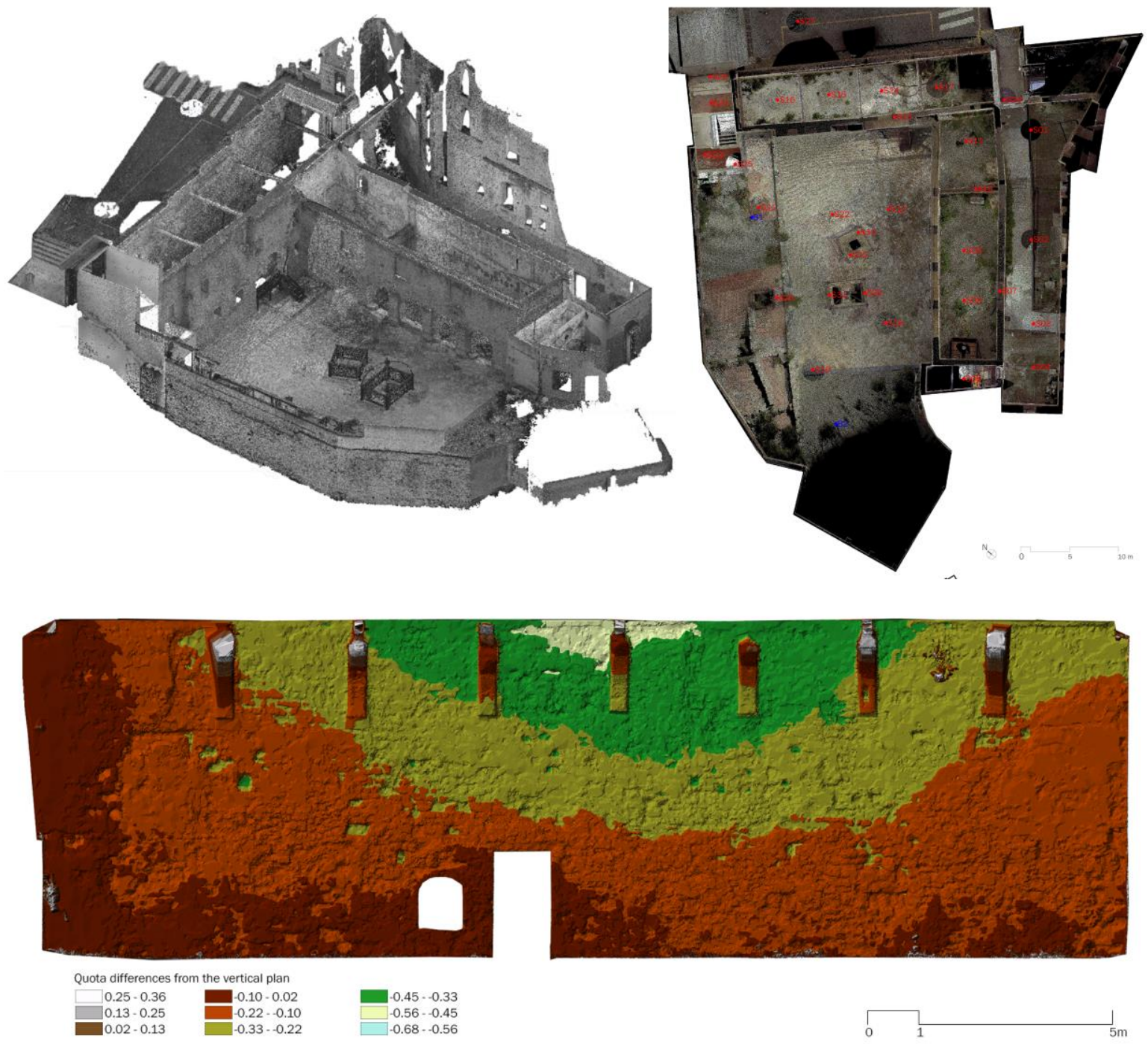

Figure 3. a) 3D non structured view of the complex; b) map of the scanning sessions; c) analysis of verticality of a masonry with ArcGis: model of verticality for a front (TLS Surveys coordinated by Vacca G.; data processing and 3D model: Dessì A., ArchGis model: Deidda M.; graphic elab.: Pilia E.).

\subsection{Stratigraphic Analysis (D.R.F.)}

Starting from these accurate survey, archaeometric investigations were carried out with an archaeological approach consisting of stratigraphic building analysis, mineral petrographic investigations of historic materials, and the identification and analysis of building techniques. Stratigraphic analysis, carried out both on the elevations and in plan, followed two lines of inquiry aimed at reconstructing its relative chronologies: on the one hand, stratigraphic analysis of the interfaces and layers, conducted for all masonries, offered the first evidence of hypothetical chronologies, still unresolved for the scarce archival material. On the other, accurate plan analysis carried out with the support of the horizontal sections performed with the TLS technique provided the opportunity to identify significant plan sections that help to define the ruin's more detailed chronology and evolution.

Overall, this analysis was carried out both on the elevations and in plan. Concerning the analysis of the elevations, it sought to identify homogenous areas in the masonries in terms of materials and building techniques. These are called USM (Masonry Stratigraphic Units), USR (Facing Stratigraphic Units) and USN (Negative Stratigraphic Units) that represent all subtractions from and cuts or additions in the masonry. As it can be seen on fig. 4a, after the individuation of all the homogenous areas (US) and their numbering, it has been essential to understand their relative temporal relations such as contemporaneity (is linked to/ $\mathrm{A}$ is contemporary $\mathrm{B}$ ), 
posteriority ( $\mathrm{A}$ is later than $\mathrm{B}$, or $\mathrm{A}$ covers $\mathrm{B}$ ), anteriority ( $\mathrm{A}$ is earlier than B, A is covered by B). The stratigraphic Units (US) were named according to room numbers and elevation letters and have been identified giving special attention was placed on the edges of each US. All the masonries have been carefully studied under this archaeological perspective, arriving at the definition of the Harry's diagram (figure 4), the matrix, and at the interpretation of a general chronology divided in 'relative phases' because of the absence of certain benchmarks.

Looking at the analysis of the plan sections, they have instead allowed understanding of important geometries such as those linked to the additions. In this case, the 10 main significant plan sections (table 1) were drawn in order to better understand the structural morphology and codify a hypothetical plan chronology (figure 5).

\begin{tabular}{|l|c|c|}
\hline $\begin{array}{l}\text { N. of } \\
\text { section }\end{array}$ & Metres from the 0 & Metres above the sea \\
\hline 1 & 0.0 & 34 \\
6 & 0.5 & 34.5 \\
11 & 1 & 35 \\
16 & 1.5 & 35.5 \\
21 & 2 & 36 \\
26 & 2.5 & 36.5 \\
31 & 3 & 37 \\
33 & 3.2 & 37.2 \\
36 & 3.5 & 37.5 \\
41 & 4 & 38 \\
\hline
\end{tabular}

Table 1. Number of sections analysed and high from the sea level and the quote 0 (Pilia E.).

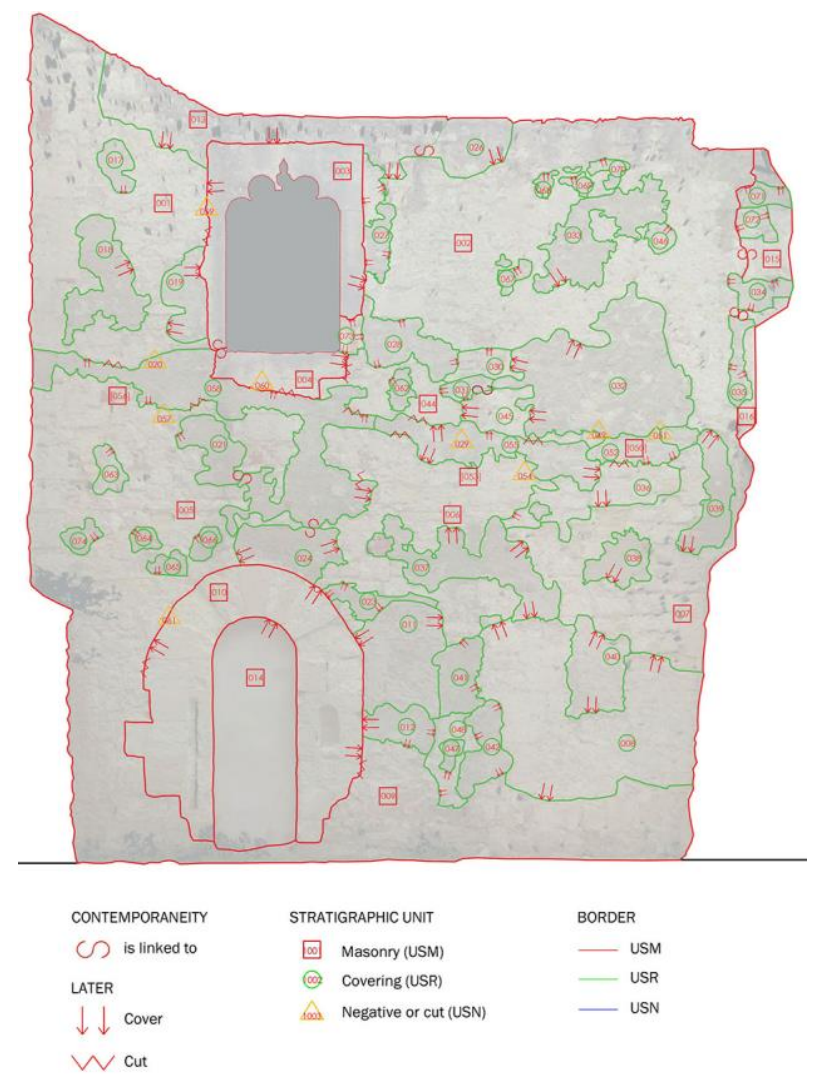

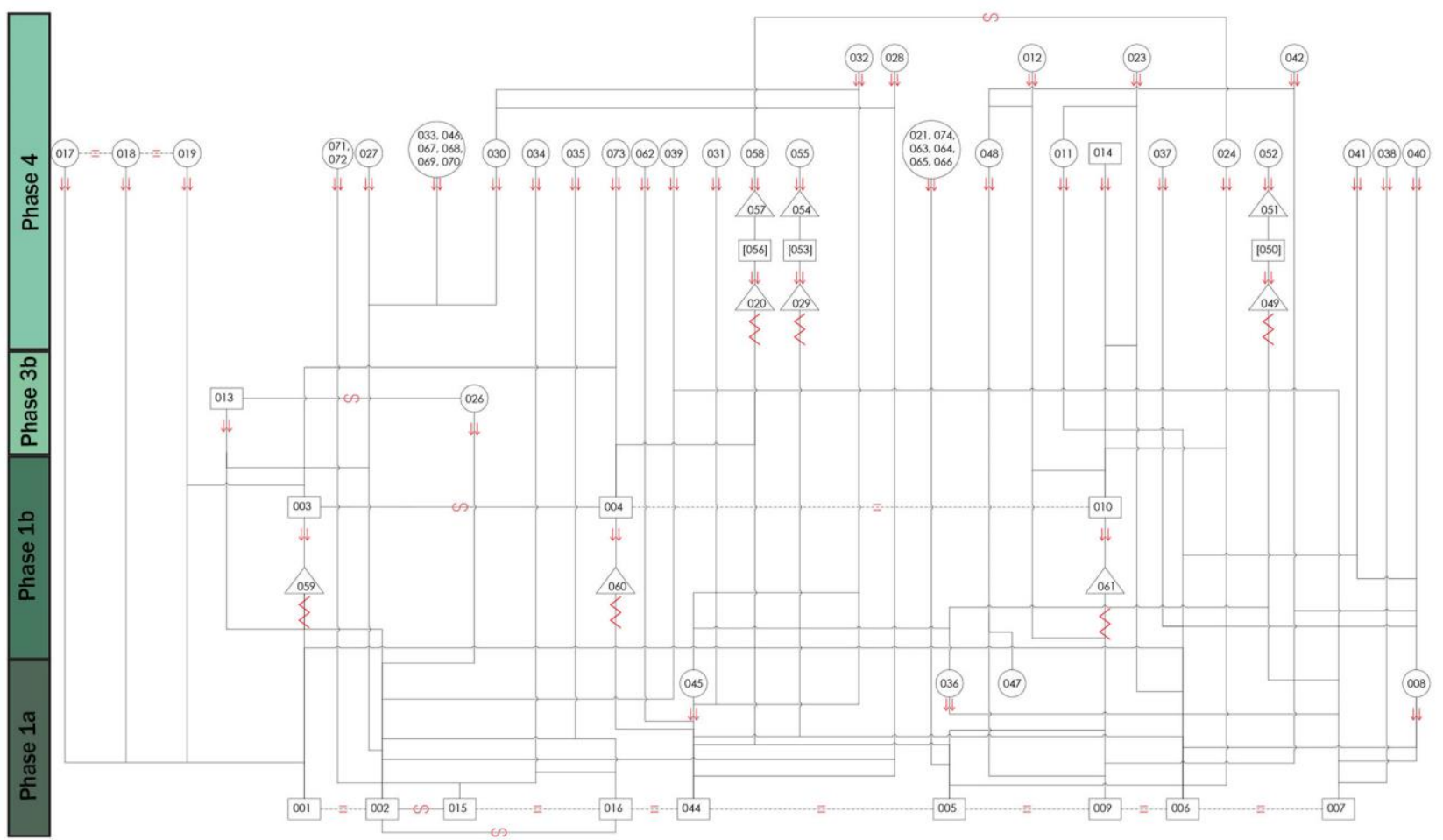

Figure 4. a) Stratigraphic analysis of a masonry; b) Harry's diagram with the relative chronology (the stratigraphic analysis has been carried out in collaboration with the Masterclass in Architectural Restoration a.a.2017-2018, prof. Fiorino D.R., tutor Pilia E. (graphic elab.: Loi M.). 

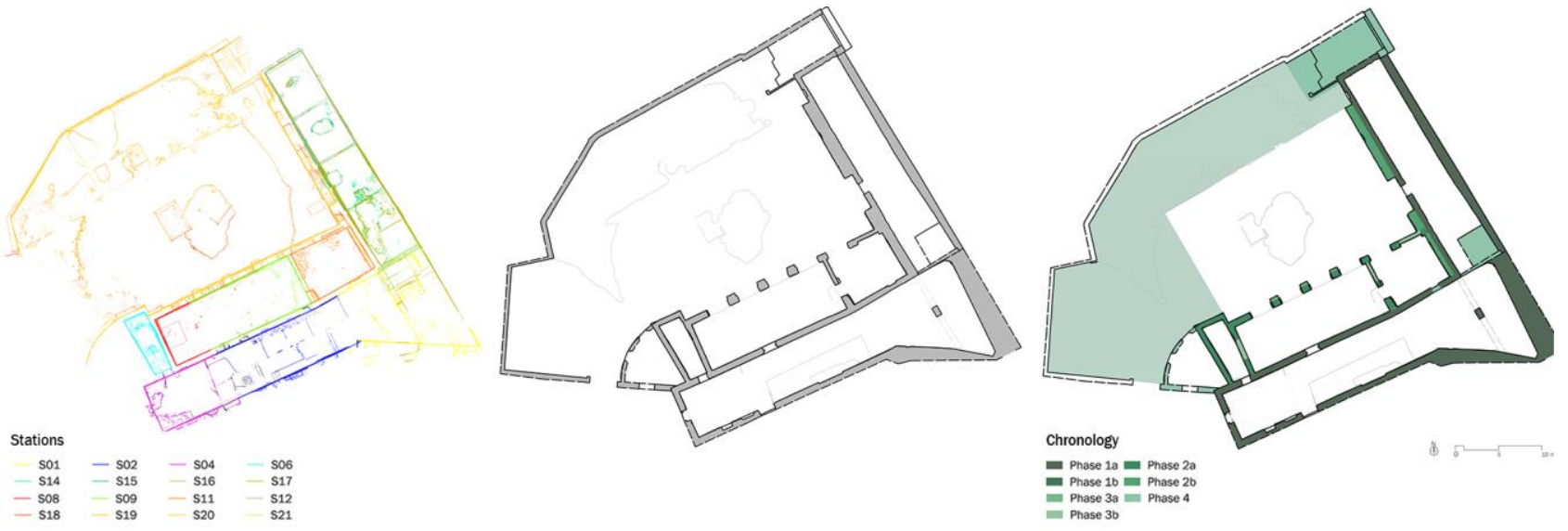

Figure 5. a) Map of the 10 main significant plan sections used to draw the plan b); c) summary of chronologies (research and graphic elab.: Pilia E.).

\subsection{Analysis of materials (S.M.G, E.P.)}

For clarifying the stratigraphic analysis and understanding of the relative chronologies, a mineral-petrographic analysis was conducted. The protocol considered a rational sampling in view of the different kinds of mortars used, where and how they were placed, also taking into account the previous investigations. The sampling was made according to specific goals: the qualitative characterisation of the materials due to their compatible reintegration and the identification of their chrono-typology to support the building's overall chronology given by the stratigraphic analysis of the masonries. The stratigraphic and minero-petrographic analyses of the building ultimately led to the classification of specific masonry techniques, widely influenced not only by economic and cultural factors, but also by local geological features and native materials with their mechanical and technological properties.

The protocol consisted in the selection of the reasoned samples, their study by means of transmitted and reflected light microscope and the study of the aggregate and the binder, separately by means of X-ray diffractometer.

After a first macroscopic analysis and the identification of similarities and differences, only 14 of the 20 samples were fully investigated. The miner-petrographic analysis was conducted by reading thin sections under the optical microscope with the purpose of studying structural and compositional characteristics; it was finished with the mineralogical investigation under X-ray (XRD), verifying the presence and composition of minerals. After the analysis, a comparative assessment of the similarities between mortars led to the definition of mortar typologies, relating, in fact, to different building construction phases and craftmanship. In general, all the mortars are local and clearly harvested from nearby quarries and shores and composed by lime binders with an aggregate mainly of feldspar, quartz and sometimes with bioclastic elements and fragments of rocks.

Differences can be found in the relationship binder/aggregate, presence or absence of lumps, "remnants of burning", and so on. From these properties come different ways of reaction to the weathering processes. In figures 6 are presented three of the most representative mortars. In details, the first one 4B_M02, macroscopically compact and with cream colours shows the presence of bioclastic components and small millimetric black aggregates. The thin sections present a homogenous structure with low presence of very small aggregate. This type of mortar can be connected to the first phases of construction.

The second one, 5A_M01, is characterised by the exclusive presence of lime as a binder component while aggregate is absent. In this case, the thin section shows a fat mortar that justifies the function of this mortar used to fill the joints in refined construction elements such as entrance arches.

The third one instead, corresponds to a second phase of restoration with the addition of new walls. In this case, this typology of mortar 4B_M01, shows the presence of an unrefined mixed aggregate and calcite as binder. The presence of cracks and voids distinguish these mortars from the others. Three typologies, according to the presence of calcite, can be recognised in a hypothetical new phase.

Finally, other samples, always based on lime binders, characterised by a very high percentage of quartz and illite, lead us to imagine to another phase, the mortar used to fill the arches of the convent after the 1908. In this case, the presence of gypsum uniquely characterises this material, which is quite friable.

\subsection{Masonry techniques (E. P.)}

The stratigraphic and minero-petrographic analyses of the building ultimately led to the classification of specific masonry techniques, widely influenced not only by economic and cultural factors, but also by local geological features and native materials with their mechanical and technological properties. In particular, the exclusive use of the pietra cantone, an easily workable stone harvested in the nearby San Guglielmo quarry, characterises the building technologies used in the Santa Chiara Convent. Starting from stratigraphic analysis, the investigation highlighted three main categories of historical building techniques depending on the typology, shapes and patterns of the stonework (figure 7): in squared blocks M01, in rough stone M02 and M03.

The M01 typology is characterised by squared blocks $(25 \times 40$ $25 \mathrm{~cm}$ ). This technique characterises all the older masonries although in some rooms, numerous restoration interventions highly modified the original appearance with several additions of other facings in pietra cantone as well. Squared blocks, although of different dimensions, were also used for constructing the arches and portico openings. 
M02 instead, is widely used in all the rest of the building. This rough typology, certainly plastered, was realised with an irregular pattern with ashlars of different dimensions and shapes. Finally, a third historical building technique, M03, is present in all the arches closed off at the beginning of the 20th century. These masonries were certainly realised with reutilized materials from the same building and built without proper techniques. The mortars of this typology were based on lime binders even if some soil was added to the mixture. Other two techniques were used in portico buttress and in the brickwork used to close up windows and doors. These typologies are indeed recent: the first, relating to the buttress, was probably realised at the beginning of 20th century along with the brick additions.
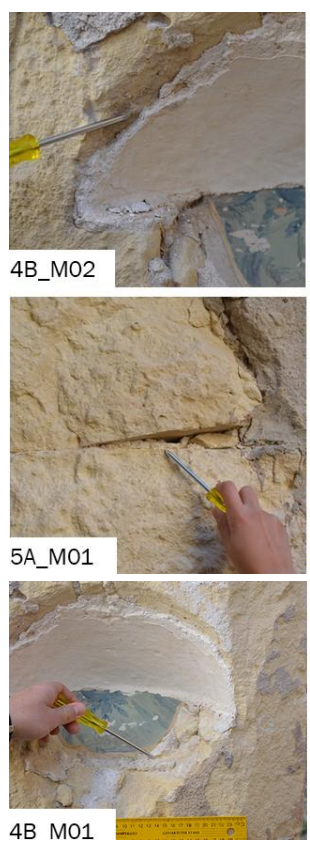
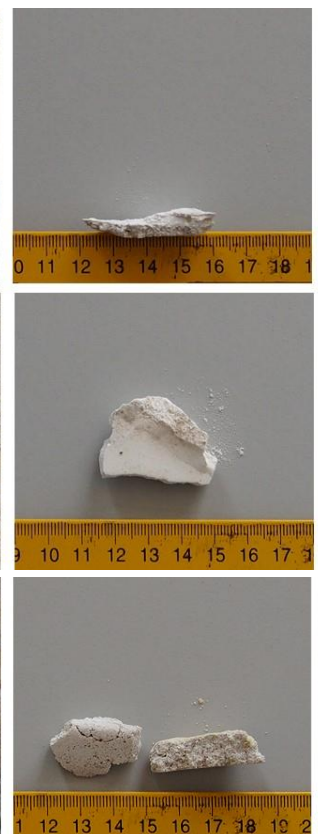
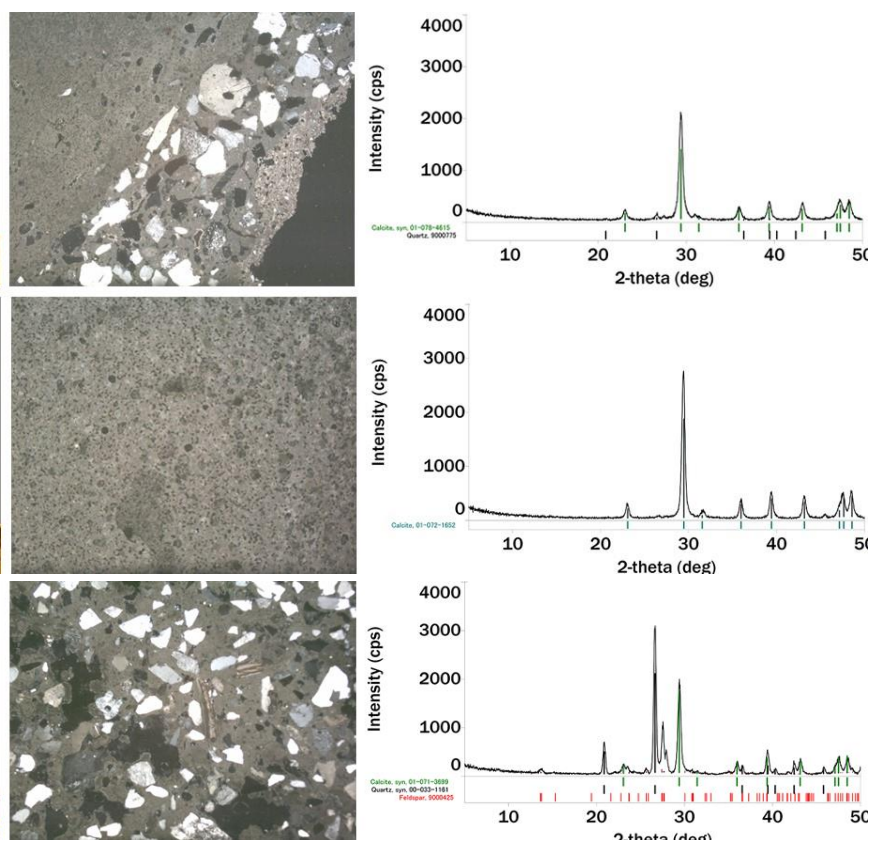

Figure 6. Minero-petrographic analysis. From the left: a) localisation of the sample; b) macro photo; thin sections under the optical microscope in Transmitted Light and X-Ray diffraction analysis (Laboratory analysis: Grillo S.M., LabMaST. Graphic elab: Pilia E.).
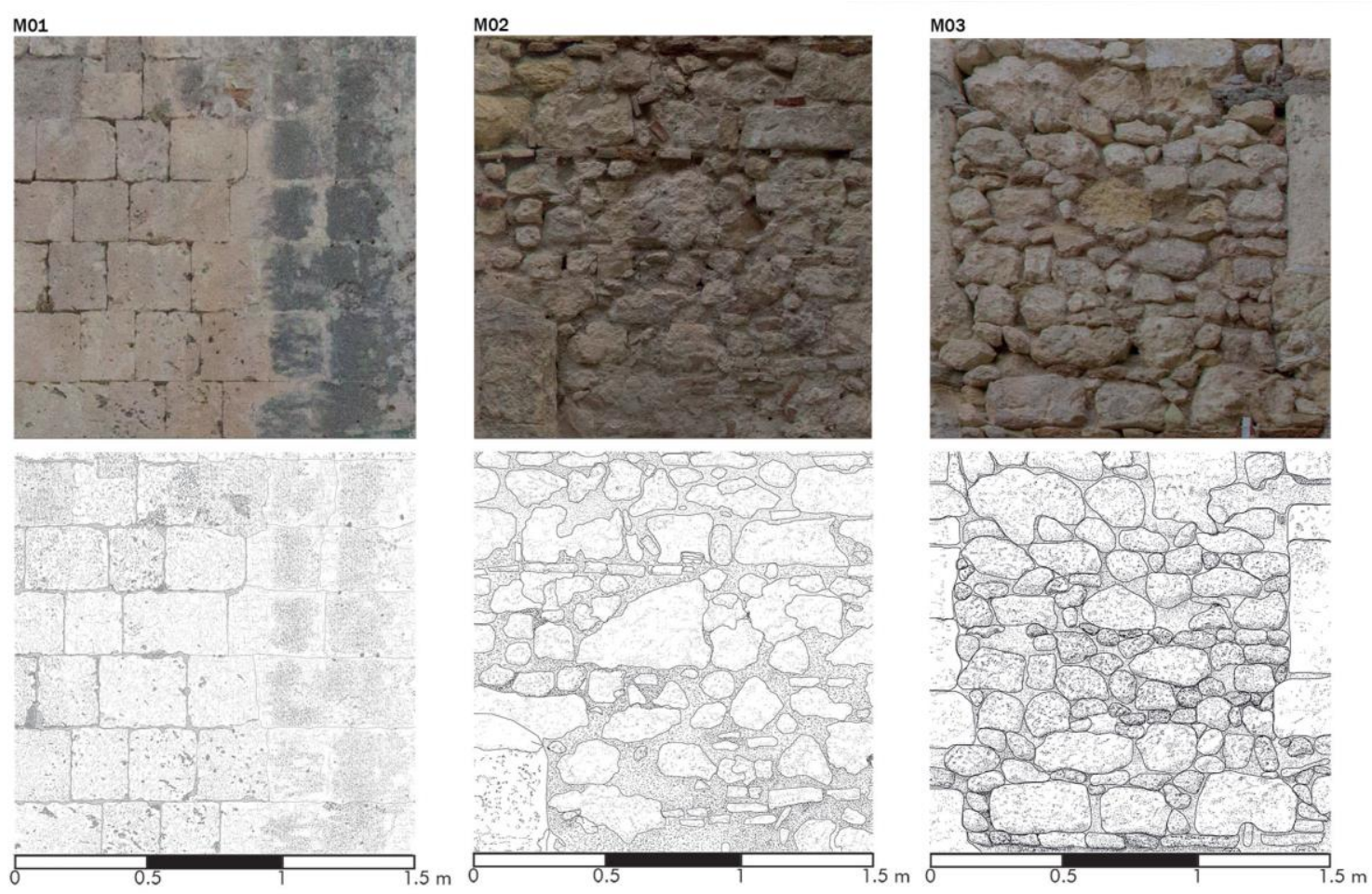

Figure 7. Masonry typologies (the analysis of building techniques has been carried out in collaboration with the Masterclass in Architectural Restoration a.a.2017-2018, Fiorino D.R., tutor Pilia E., (graphic elaboration: Loi M., Pinna M., Mura G.) 


\section{RESULTS AND DISCUSSION}

Thanks to these investigations, it was therefore possible to provide a hypothesis of the possible evolution of the complex since it was built in the 14th century on the pre-existing church of Santa Margherita. In summary, four main phases can be identified. A first phase (1a) relates to the construction of a first wing, connected to the first church. The little embrasure in a room might confirm this hypothesis along with the uniform building techniques and mortars.

A subsequent phase (1b) can be added because of the hypothetical opening of arch passages characterised by different mortars. These are probably the result of openings created in the original walls. The main portal and the decorated window are clearly stylistically datable to the Aragon period. Thus, this phase might be attributed to the 15 th century.

Then, phase $2 \mathrm{a}$ can be indirectly dated to the 17 th century when Alfonso Laso Sedeno decided to restore the dormitory, to build new walls and to refurbish the cistern and other parts of the cnvent (Ingegno, 1993). All the archaeological remains, the floors, the arches and the stoup can be attributed to this phase. Immediately thereafter, in phase $2 b$, as clearly evidenced by the analyses carried out with the 3D model of the convent and from analysis of the vertical sections, can be reported a portion of wall that could have been added as support of the unstable original wall and as consequence, it overlaps the arcade $6 \mathrm{~b}$. With the erection of this wall, all the openings of the wall $7 \mathrm{c}$ were closed and the new ones adapted to the pre-existing conditions. At this point the building's configuration was the same as the one represented in 1908 by the surveyors.

Then, a third phase can be dated after this state. In phase $3 \mathrm{a}$, it can be supposed that the buttresses supporting the arches were constructed. Then, in phase $3 \mathrm{~b}$, it can be presumed that all the closures of the arches opened in the second phase were done. This is because they still appeared accessible in the 1908 cartography. A final phase saw all the enclosing walls realised in bricks and the modern plasters used to fill the void created by the market.

In conclusion, the methodology carried out, has allowed to understand and study the building's forms, geometries, materials, developments, and chronologies of the complex. It has also permitted us to recognise characteristic features and anomalies, structural morphology, and other structural issues macroscopically not visible.

Lastly, these results can be the basis for other further investigations and analyses as well as the assessment of spatial, architectural, historical and artistic values, for the definition of possible sustainable project of reuse of this area

\section{REFERENCES}

Doglioni, F., ed. 1997. Stratigrafia e restauro, tra conoscenza e conservazione dell'architettura, Trieste: Lint.

Fiorino, D. R., Pilia, E. 2014. "Il rudere come Time-Landmark del paesaggio storico". The International and Interdisciplinary periodical. Agribusiness Paesaggio \& Ambiente, XVII no. 2: $108-114$.

Fiorino, D. R., Grillo, S. M., Pilia, E. 2015. "Interdisciplinary Knowledge for Conservation of Ruins: Stratigraphic Investigations of San Giovanni Battista Church (Sardinia, Italy)". Athens: ATINER'S Conference Paper Series, No: ARC2015-2123.

Fiorino, D. R., Grillo, S. M., Pilia, E. 2016. "Historical mortars as record in the knowledge of ruins". Proceedings of the 4th
Historic Mortars Conference - HMC 2016. 10-12 October 2016, Santorini, Greece, edited by Papayianni, I., Stefanidou, M. \& Pachta V., 779 - 256. Laboratory of building Materials, Department of Civil Engineering Aristotle University of Thessaloniki, ISBN: 978-960-99922-3-7.

Fiorino, D. R., 2015. "Stratigraphy and analysis of interfaces for the preservation of architectural heritage". International journal of sustainable development and planning, 10(5), 755 - 766.

Giannattasio, C., Grillo, S.M., Vacca, G. 2013. "Interdisciplinary study for knowledge and dating of the San Francesco Convent in Stampace, Cagliari - Italy (XIII-XXI Century)". ISPRS Ann. Photogramm. Remote Sens. Spatial Inf. Sci., II-5/W1, 139-144, doi:10.5194/isprsannals-II-5-W1-1392013, eISSN 2194-9050

Grillo, S.M. 2009. "Le pietre usate nel costruito". Proposte per Stampace. Idee per in piano di conservazione del quartiere storico di Cagliari, Giannattasio, C., Scarpellini, P. (eds.), Gangemi Editore, Rome.

Ingegno, A. 1993. Santa Chiara: restauri e scoperte, Cagliari.

Pilia, E. 2017. "Urban ruins in historical centres. An integrated methodology for sustainable interventions in Cagliari, Sardinia". ArcHistoR architettura storia restauro - architecture history restoration, anno IV no. 8, 174-217, ISSN 2384-8898.

Pilia, E. 2019. Urban ruins. Memorial value and contemporary role, DOM Publishers: Berlin, ISBN 978-3-86922-708-5.

Pilia, E., Pirisino, M.S. 2016. "Gaining knowledge of materials and chronologies of the ruins for the preservation of historical centers: the case study of Monteleone Rocca Doria in Sardinia (Italy)". HERITAGE 2016 - Proceedings of the 5th International Conference on Heritage and Sustainable Development, Green Lines Institute edited by Lira, S., Mano, A., Amoêda, R. \& Pinheiro C., 1395-1404. Lisbon.

Stephenson, J., 2008. "The Cultural Values Model: An integrated approach to values in landscapes". Landscape and Urban Planning 84, 127-139.

Vacca, G., Deidda, M., Dessi, A., Marras, M. 2012. "Laser scanner survey to cultural heritage conservation and restoration", Int. Arch. Photogramm. Remote Sens. Spatial Inf. Sci., XXXIX-B5, 589-594, doi:10.5194/isprsarchives-XXXIXB5-589-20. 